\title{
O posicionamento do Brasil nas negociações internacionais sobre temas de meio ambiente
}

\section{The POSITION OF BRAZIL IN INTERNATIONAL NEGOTIATIONS REGARDING ENVIRONMENTAL ISSUES}

\author{
Wilson Almeida* \\ Débora Rodrigues** \\ Hadassah Santana***
}

* Wilson Almeida: Pós-Doutor pela University of Wis c on s in - M a dis on/ Georgetown University. Diretor da Escola de Direito da Universidade Católica de Brasília. Professor do Mestrado em Direito da Universidade Católica de Brasília. walmeida@ucb.br

** Débora Rodrigues: Mestre em Relações Internacionais com orientação em Economia Internacional pela Universidad de Buenos Aires (UBA).

*** Hadassah Santana: Mestranda em Direito pela Universidade Católica de Brasília - UCB. Professora da pós-graduação em Direito Tributário e Finanças Públicas no Instituto Brasiliense de Direito Público - IDP. hadassah.santana @gmail.com
Resumo: Este estudo tem como objetivo geral a análise da participação brasileira nas negociações ambientais internacionais no período de 1972 (Estocolmo) a 1997 (Kyoto). Especificamente, analisar as conferências ambientais internacionais; em particular, seus objetos e conteúdo que propiciaram a evolução do conceito de desenvolvimento sustentável; identificar o posicionamento brasileiro em cada uma das conferências, ressaltando as negociações brasileiras para a solução da problemática ambiental; e por último uma análise da aceitação no âmbito nacional do conceito de desenvolvimento sustentável e a evolução se sua inserção no pensamento político ambiental brasileiro. A fundamentação teórica está assentada nas teorias do Realismo, Liberalismo e Cooperação Internacional. A conclusão retrata, além da comprovação da hipótese e o atingimento dos objetivos, que a discussão do meio ambiente transferida para o campo das relações internacionais gerou convenções primordiais em busca de um universo sustentável; que a importância da atuação brasileira em tais conferências abordadas serviu, além de mediação, à inovação para o desenvolvimento de ações concretas para a consolidação do conceito de sustentabilidade; e finalmente que a análise levada ao efeito nas seções I, II e III favoreceu a evolução do pensamento político ambiental no País. Com base nos resultados alcançados, sugeriu-se a profusão de novas pesquisas com vistas a destacar a importância do meio ambiente no contexto das relações internacionais.

Palavras-chave: desenvolvimento; negociações internacionais; relações internacionais; sustentabilidade.

Abstract: This study aims at the analysis of the overall Brazilian participation in international environmental negotiations in the period from 1972 (Stockholm) to 1997 (Kyoto). Specifically, analysis of the environmental international conference, its 
objects and contents which provided the evolution of the sustainable development concept; to identify the Brazilian position in each conference, drawing a particular attention to the Brazilian negotiations for the environmental problems solution and finally an analysis of acceptance on the national level of the sustainable development concept and the progress of its inclusion in the Brazilian Environmental Policy. The theoretical reasoning is based on Realism, Liberalism and International Cooperation theories. The conclusion portrays, in addition to the evidence of the hypothesis and the goals achievement, that the discussion of the environment transferred to the international relations field realized fundamental conventions in search for a sustainable world; that the importance of the Brazilian performance in such addressed conferences served, besides mediation, as innovation in the development of concrete actions to the sustainable consolidation concept and, at last, that the analysis brought to the end of sections I, II and III encouraged the progress of the Environmental Political thought in the country. Based on the achieved results, it was suggested the profusion of new researches in order to highlight the importance of the environment in the context of international relations.

Keywords: development; international negotiations; international relations and sustainable. 


\section{INTRODUÇÃO}

Este estudo tem como objetivo geral a análise da participação brasileira nas negociações ambientais internacionais no período de 1972 (Estocolmo) a 1997 (Kyoto). Especificamente, analisar as conferências ambientais internacionais; em particular, seus objetos e conteúdo que propiciaram a evolução do conceito de desenvolvimento sustentável; identificar o posicionamento brasileiro em cada uma das conferências, ressaltando as negociações brasileiras para a solução da problemática ambiental; e por último uma análise da aceitação no âmbito nacional do conceito de desenvolvimento sustentável e a evolução se sua inserção no pensamento político ambiental brasileiro.

A fundamentação teórica está assentada nas teorias do Realismo, Liberalismo e Cooperação Internacional. A conclusão retrata, além da comprovação da hipótese e o atingimento dos objetivos, que a discussão do meio ambiente transferida para o campo das relações internacionais gerou convenções primordiais em busca de um universo sustentável; que a importância da atuação brasileira em tais conferências abordadas serviu, além de mediação, à inovação para o desenvolvimento de ações concretas para a consolidação do conceito de sustentabilidade; e finalmente que a análise levada ao efeito nas seções I, II e III favoreceu a evolução do pensamento político ambiental no País. Com base nos resultados alcançados, sugeriu-se a profusão de novas pesquisas com vistas a destacar a importância do meio ambiente no contexto das relações internacionais.

\section{A CAMINHAdA DO BRASIL NA PROTEÇÃO AO MEIO AMBIENTE}

As questões ambientais assumiram uma posição relevante no contexto internacional a partir da realização da Conferência de Estocolmo em 1972, que teve como objetivo fortalecer a ação governamental, bem como fornecer diretrizes para a proteção do meio ambiente, por meio da cooperação internacional (Brasil, 1991, p.180).

Entre 1960 e 1979, o Brasil usufruiu de ganhos expressivos do desenvolvimento econômico, devido à estratégia adotada baseada, principalmente, na utilização intensa dos recursos naturais para a produção de petróleo, álcool e extração mineral. Embora a comunidade internacional se interessasse cada vez mais pelos problemas ambientais, os países emergentes e especialmente o 
Brasil lideravam alianças para não enfatizar o problema nas sociedades dos países em desenvolvimento (Viola, 1998, p.09).

Por conter grandes reservas de recursos naturais, entre os quais as maiores de água potável do mundo, além de ser repositório de boa parte da biodiversidade do planeta, responsável por $20 \%$ do total de espécies mundiais, ou seja, 340 mil espécies o Brasil é alvo de constante atenção em outras partes do mundo (Vargas, 2002, p. 231).

A partir de 1972, consolidou-se internacionalmente a percepção de que o Brasil não seria capaz de preservar esse extraordinário patrimônio; essa percepção se fortaleceu ainda mais nos anos subseqüentes, sendo mais grave na segunda metade dos anos 1980, em razão da repercussão da intensificação de queimadas na Amazônia.

A Conferência de Estocolmo, ocorrida em 1972 e divulgada, a partir da publicação do Relatório de Brundtland em 1987, desenvolveu o conceito do desenvolvimento sustentável que está fundamentado em um tripé resumido nas seguintes sentenças: economicamente viável, socialmente justo e ecologicamente equilibrado. Essa linha de desenvolvimento tem sido um vetor importante nos diversos debates no tocante ao crescimento econômico e à sustentabilidade (Brasil, 1993, p. 69).

Nesse contexto, o conceito contribui para compreender e enfrentar os problemas atuais da humanidade relacionados ao meio ambiente, além de representar uma transformação profunda nas relações internacionais com a construção de uma nova ordem ambiental mundial.

Diante de todos os esforços mencionados e, principalmente, a partir de uma nova concepção paulatinamente estabelecida pelos atores internacionais no tocante a problemática ambiental a agenda ambiental que se restringia à questão dos recursos naturais e à degradação assimétrica do solo expandiu-se de forma considerável e o Brasil começou a sinalizar uma postura mais sensível no que diz respeito às responsabilidades ambientais (MACHADO \& RODRIGUES, 2006, p. 196).

Após a Conferência de Estocolmo, foi realizada a Conferência Rio 92, que contribuiu enfaticamente para a ampliação, em escala mundial, da consciência do ambientalismo, ou seja, a participação de diferentes atores dentre eles a sociedade civil, os organismos não governamentais, que contribuem para a realização de medidas mais efetivas para a preservação ambiental tanto no Brasil, como no âmbito internacional. 
O Brasil, que demonstrava em 1972, o seu não envolvimento com as questões ambientais, passou a adotar um posicionamento mais favorável, a ponto de ser candidato para sediar umas das maiores conferências internacionais na área, desempenhando um papel de destaque que merece ser amplamente discutido, no debate criado e fomentado internacionalmente em torno do desenvolvimento sustentável.

Ao sediar a Rio-92, o Brasil buscava demonstrar que seria possível preservar a "soberania sobre os recursos naturais, principalmente os amazônicos" além de aproximar as posições dos países desenvolvidos e atuar de maneira decisiva nas negociações sobre "menção ao desenvolvimento social e econômico em bases sustentáveis" (Brasil, 1991)

A Conferência mencionada desenvolveu documentos importantes, que previam bases para ações globais perante as questões de desenvolvimento econômico e os impasses ambientais; entretanto, as dificuldades encontradas no desenvolvimento e na implementação de políticas para o controle e avanço acelerado da degradação ambiental eram notórios. Mesmo assim, o Brasil ainda realizava esforços que contribuíam para a sensibilização nacional e internacional no que diz respeito ao meio ambiente (PNUD).

O desenvolvimento sustentável suscitou novas discussões que deram origem, em 1997, ao Protocolo de Kyoto, segundo o qual os países industrializados devem reduzir a emissão de gases do efeito estufa pelo menos em 5\% entre 2008 e 2012. A atuação do Brasil nas negociações do Protocolo baseava-se na definição do interesse nacional, que buscava promover a visão do desenvolvimento integrada com o uso racional dos recursos naturais (Sarney, 2004, p. 13).

O Brasil estabeleceu com mais 160 países, o conceito do Mecanismo de Desenvolvimento Limpo (MDL), instrumento para a redução das emissões de gases que causam o efeito estufa, que é caracterizado como um fenômeno que ocorre de forma natural na atmosfera nos quais alguns gases como dióxido de carbono é capaz de reter o calor do sol. Porém, o aumento da emissão de tais gases provoca o efeito estufa e o aumento da temperatura na terra (Sarney, 2004, p.13).

Com esse mecanismo, os países desenvolvidos que não cumprirem suas metas de emissão podem compensar o problema financiando projetos de redução da poluição em países emergentes. O Brasil teve um papel relevante na promoção das negociações do Protocolo de Kyoto e assumiu a liderança na 
articulação de alianças entre os países emergentes, que contribuiu para o crescimento de seu prestígio no âmbito internacional.

\section{ANÁLISE DAS CONFERÊNCIAS AMBIENTAIS INTERNACIONAIS}

Os anos 1970 representaram uma década de crise, recessão mundial e extenuação do modelo de crescimento adotado no pós-II Guerra (1939-1945). As crises do petróleo de 1973 e 1979 constituíram o elemento crucial para "a queda de um longo ciclo ascendente da economia capitalista," de modo que o aumento do preço do petróleo produziu grandes déficits nos balanços de pagamentos dos países que não eram produtores (MAGNOLI, 1996, p. 147).

Diante de um panorama de instabilidade no sistema financeiro internacional e desenvolvimento, prevalecia na humanidade a idéia de que os recursos naturais eram ilimitados ao deteriorar-se um determinado recurso a ponto de não "oferecer a sustentabilidade de antes, haveria uma nova fronteira a qual expandir as atividades econômicas" (Brasil, 1991).

Em 1972, a Conferência de Estocolmo, organizada pela Organização das Nações Unidas, foi um marco inicial para a discussão a respeito das diferentes condições de desenvolvimento, bem como as devidas responsabilidades de cada país em relação às questões ambientais (CALSING, 2005, p. 35).

Entre as contribuições da Conferência pode-se destacar o dever ao desenvolvimento sem agressão ao meio ambiente; a criação do Programa das Nações Unidas sobre o Meio Ambiente (PNUMA), bem como a ampliação da abrangência de atuação da opinião pública em debater medidas mais efetivas para a proteção dos recursos naturais (CALSING, 2005, p.36).

Entretanto, a principal conquista obtida em Estocolmo foi o impulso inicial ao Relatório Brundtland, publicado em 1987, no qual se elaborou o conceito de desenvolvimento sustentável, que define estratégias bem elaboradas de transformações de setores produtivos essenciais para a economia e bem-estar da sociedade (Brasil, 1991, p. 159).

Nos termos do Relatório Brundtland, o conceito de desenvolvimento sustentável demonstrava a possibilidade de integrar a questão ambiental à problemática socioeconômica que, segundo Marina Silva, ex Ministra do Meio Ambiente do Brasil, retoma "o crescimento econômico com uma política ambiental transparente e multifacetada base da governabilidade". 
Tal fato mencionado levou o meio ambiente a ser reconhecido como um assunto de grande relevância, tanto que passou a ser amplamente discutido pela opinião pública brasileira de maneira que não poderia ser mais renegado pelos governos (CALSING, 2005, 35).

Em 1989, a Resolução 44/228, adotada pela ONU, estabeleceu a realização da Conferência das Nações Unidas sobre Meio Ambiente e Desenvolvimento em 1992, tendo como sede o Brasil, especificamente a cidade do Rio de Janeiro: essa conferência ambiental foi concebida como a maior no mundo até então, tendo seus objetivos delimitados em quatro grupos.

O primeiro previa o estabelecimento de estratégias e recomendações de medidas no âmbito nacional e internacional, na tentativa de conter a degradação ambiental. O segundo dizia respeito a programas para promover um desenvolvimento sustentável; o terceiro visava à "capacitação de pessoas, cooperação técnica e educação ambiental" e o quarto referia-se as questões institucionais, bem como aos recursos financeiros destinados ao evento (Brasil, 1993, p. 16).

Em 1990, iniciaram-se os trabalhos pelo Comitê Preparatório que realizou a I Sessão Organizacional em Nova York esse grupo apresentou alguns entraves devido à resistência, por parte dos países desenvolvidos, quanto as discussões envolvendo as questões ambientais e o desenvolvimento e a Sessão II, realizada em Genebra, procurou enfatizar os princípios jurídicos e institucionais, bem como a realização de consultas antes da Conferência e regras de procedimentos (Brasil,1993, p.16).

A Declaração do Rio retomou o legado de Estocolmo, intensificou as preocupações no tocante à temática ambiental e destacou, em seu Princípio 3 que o desenvolvimento sustentável deve ser exercido de modo que sejam atendidas eqüitativamente as necessidades de desenvolvimento e do meio ambiente das gerações presentes e futuras (Ministério do Meio Ambiente).

Porém, a Declaração ao ser apresentada sofreu reações por parte da Argentina - por não conter no texto proposto por Tommy Koh presidente do comitê o tema de políticas agrícolas na Comunidade Européia e seus impactos sobre o meio ambiente, fato que dificultaria a finalização do texto. Porém, isso não reduziu a relevância da Declaração que defende a realização de estudos ambientais e enaltece a participação da sociedade na promoção do desenvolvimento sustentável (Brasil, 1993, P. 38).

Posteriormente, o compromisso mais importante assumido pelos Estados na Rio 92 foi o estabelecimento da Agenda 21, que atesta ações específicas 
sobre as questões de meio ambiente e desenvolvimento, contribuindo para a realização plena do conceito de desenvolvimento sustentável (Brasil, 1993, P. 21).

Organizada em 04 seções e 40 capítulos com a participação de 179 países, a Agenda 21 apresenta mais de 100 programas com ampla diversidade de temas; porém configura-se como uma soft law, na medida em que é um "acordo que não cria vínculos legais para tornar sua implementação mandatória”, o que contribui para que os países não tratem o tema com a devida importância e para que se dificulte a viabilização de tais programas (Vargas, 2002, P. 80).

O processo de planejamento da Agenda 21 não está limitado à preservação dos recursos naturais, mas abrange questões estratégicas relacionadas a emprego, a redução de assimetrias regionais e instrumentos de gestão.

Três elementos fundamentais permitiram à Agenda 21 se tornar um documento de grande relevância e de base para ações governamentais: um mecanismo financeiro autônomo; um compromisso capaz de garantir um sistema eficaz de transferência de tecnologia bem como o fortalecimento das instituições para alcançar o desenvolvimento sustentável. Assim, a Agenda global enfatiza os processos de implementação de agendas locais, com o intuito de atingir uma estratégia para a sustentabilidade com a participação da sociedade civil (Vargas, 2002, p. 81).

AAgenda 21 local envolve ações coordenadas em relação aos problemas ambientais, econômicos e sociais no âmbito nacional. Nesse contexto, o Brasil enfrentou algumas dificuldades no tocante à implementação de sua Agenda, pois no governo Itamar Franco (1992-1995), as questões ambientais teriam perdido relevância em relação ao governo anterior, especialmente ao ser levadas em consideração a conjuntura interna brasileira (Vargas, 2002, p. 83).

No planejamento da Agenda 21brasileira foram escolhidos seis temas e, sobre cada um, foi realizado um trabalho de consulta a diferentes segmentos da sociedade, com o intuito de identificar os impasses, as diversas opiniões dos atores sociais, bem como propostas para o desenvolvimento da sustentabilidade (Ministério do Meio Ambiente).

Em 2000, foram desenvolvidos amplos debates no âmbito regional, que deram origem a um relatório para cada estado da federação, demonstrando a visão de cada um deles "sobre as contribuições apresentadas pelas diferentes entidades locais". Durante o desenrolar dos debates estaduais, foram discutidas 5,839 propostas correspondentes aos seis temas delimitados da Agenda Nacional. O quadro 01 elaborado pela Comissão de Política de Desenvolvimento 
O posicionamento do Brasil nas negociaÇões InTERnaCionais SOBRe temas de MEIO AMbiente

Sustentável (CPDS), vinculada à Câmara dos Recursos Naturais da Presidência de República que demonstra a participação individual ativa de cada Estado nesse contexto (Vargas, 2002, p. 90).

Quadro 01 - Representa o número de propostas nos debates estaduais da Agenda 21 Brasileira.

\begin{tabular}{|l|c|c|}
\hline \multicolumn{1}{|c|}{ ESATADOS } & $\begin{array}{c}\text { TOTAL GERAL DE } \\
\text { PROPOSTAS POR } \\
\text { ESTADO }\end{array}$ & $\begin{array}{c}\text { NÚ'MERO DE } \\
\text { PARTICIPANTES }\end{array}$ \\
\hline Alagoas & 152 & 168 \\
\hline Sergipe & 77 & 103 \\
\hline Piaú & 61 & 102 \\
\hline Maranhão & 99 & 290 \\
\hline Rio Grande do Norte & 224 & 270 \\
\hline Mato Grosso & 220 & 80 \\
\hline Santa Catarina & 425 & 100 \\
\hline Espírito Santo & 25 & 295 \\
\hline Ceará & 248 & 137 \\
\hline Paraíba & 243 & 110 \\
\hline Roraima & 120 & 193 \\
\hline Pernambuco & 575 & 119 \\
\hline Bahia & 190 & 170 \\
\hline Rio de Janeiro & 233 & 120 \\
\hline Rio Grande do Sul & 319 & 130 \\
\hline Pará & 193 & 100 \\
\hline Amazonas & 233 & 354 \\
\hline Minas Gerais & 976 & 150 \\
\hline Mato Grosso do Sul & 108 & 75 \\
\hline Acre & 90 & 160 \\
\hline Tocantins & 142 & 130 \\
\hline Rondônia & 108 & 92 \\
\hline Goiás & 218 & 161 \\
\hline São Paulo & 314 & 83 \\
\hline Distrito Federal & 104 & 3.880 \\
\hline Paraná & 139 & \\
\hline TOTAL GERAL & 1.829 & \\
\hline & & 15 \\
\hline
\end{tabular}

O Quadro 01 tem como intuito trazer à tona o total de propostas apresentadas por cada Estado que correspondem a uma participação efetiva na elaboração não apenas do processo da Agenda brasileira, mas principalmente na promoção do desenvolvimento sustentável no âmbito nacional. 
Após todos os esforços realizados, a Agenda 21 Brasileira foi lançada em 2002 e implementada no ano seguinte, sendo os seus princípios considerados um marco para a construção da sustentabilidade no Brasil. Devido a sua importância, o governo transformou em programa a Agenda 21 Brasileira no Plano Plurianual do Governo (PPA), no período compreendido entre 2004-2007, o que contribuiu para ampliar o poder e alcance de suas estratégias (Ministério do Meio Ambiente).

Portanto, é possível analisar que a Conferência Rio 92 além de democrática abarcou informações cientificas e tecnológicas, bem como pesquisas e soluções que foram cruciais para a ampliação da consciência de praticamente todos os países no tocante a problemática ambiental (Brasil, 1993, p. 68).

\section{AS MUDANÇAS CLIMÁTICAS COMO ELEMENTO PROPULSOR NAS NEGOCIAÇÕES}

Diante das temáticas apresentadas anteriormente, deve-se destacar ainda as questões relacionadas as emissões de gases causadores do efeito estufa, caracterizados pelo modelo energético estabelecido desde a revolução industrial. Em 1988, o estabelecimento do Intergovernmental Panel on Climate Change (IPCC), representou o ponto de partida para lidar com a questão climática e tentar reduzir os impactos para a vida na Terra (Vargas, 2002, p. $58)$.

O Relatório do IPCC demonstrou a relevância do tema e solicitou a criação de uma Convenção com o intuito de gerar pilares para a cooperação internacional relacionada ao aquecimento global. Assim, a ONU iniciou os trabalhos que posteriormente resultariam na Convenção Quadro sobre os Efeitos da Mudança do Clima tendo a participação de 182 países, com o intuito de estabilizar a emissão dos gases responsáveis pelo efeito estufa (CALSING, 2005, p. 42).

Tal relatório é um documento enfaticamente discutido nos últimos anos no âmbito internacional, afinal as incertezas geradas em torno do aquecimento global alertavam as delegações para a relevância do tema e do documento. Assim, a cada ano, as questões ambientais assumem um espaço de destaque nas negociações, bem como nos tratados internacionais que visam à reafirmação do multilateralismo como a chave para se concretizar o conceito de desenvolvimento sustentável. 
Atualmente, o desenvolvimento tem sido caracterizado como sinônimo de poluição. Segundo Trigueiro (2006), nos últimos 150 anos a queima progressiva de petróleo, carvão e gás garantiram a prosperidade dos países.

As estimativas desde 1860, demonstraram um aumento significativo nas taxas de emissão de gases de efeito estufa (GEE), de 7 bilhões de toneladas de carbono emitidos na atmosfera, apenas 4 bilhões de toneladas são absorvidos pela natureza. Nesse sentido, o acordo do Clima assinado por 175 países na Rio-92, reconhecia uma estratégia global para combater as mudanças climáticas.

Em 1997, instituiu-se o Protocolo de Kyoto um tratado internacional que regulamenta a Convenção Quadro das Nações Unidas (UNFCC), com objetivo de reduzir as elevadas taxas de emissão de GEE. No decorrer das negociações do Protocolo, a CE demonstrou grande sensibilidade ao tema e por apresentar um desenvolvimento tecnológico satisfatório passou a elaborar alternativas com baixo custo para conter a poluição.

Porém, para os países da Organização dos Países Exportadores de Petróleo (OPEP), as reduções das emissões podem provocar impactos significativos em suas economias, por serem produtores e exportadores de petróleo. Porém, diante do contexto o Brasil se destacou assumindo um posicionamento de liderança em diversas negociações do Protocolo.

Calsing (2005, p.61), destaca que as negociações do Protocolo atingiram seu ápice na Conferência das Partes da Convenção Quadro das Nações Unidas sobre Mudança do Clima (COP 07), na qual foram definidas as regras operacionais (Acordos de Marraqueche); além disso, a apresentação do terceiro relatório do IPCC contribuiu para alertar os países para a gravidade do problema agilizando o processo de negociação.

Assim, o protocolo de Kyoto determina que as Partes listadas no seu Anexo I, ou seja os países desenvolvidos, reduzam suas emissões em 5,2\% no período correspondente entre 2008 e 2012. Porém, as diretrizes do Protocolo não se limitam a reduções dos GEEs. As Partes do Anexo I precisam ainda incentivar uma agricultura sustentável, o desenvolvimento de energia sustentável, bem como mecanismos tecnológicos para a absorção do carbono (CALSING, 2005, p. 79).

Nos termos do Artigo 67, definido nos Acordos de Marraqueche, documento que estabelece as regras do Protocolo de Kyoto, quando uma Parte não está cumprindo o Artigo 5, parágrafo 1 ou parágrafo 2 ou o Artigo 7, parágrafo 1 do Protocolo, o ramo coercitivo deverá submeter o Parte a um 
plano de ação para análise dos requisitos que conduziram ao não cumprimento dos objetivos estabelecidos.

Ainda de acordo com Renata Calsing (2005, p.97), a aplicação de sanção para a Parte que descumprir os seus compromissos deve seguir o principio "due process of Law," garantindo a segurança jurídica, a justiça e a imparcialidade. As sanções aplicadas pelo Protocolo não são de caráter financeiro, já que esse tipo de punição provocaria uma resistência ainda maior por parte dos países em ratificarem o mesmo, porém apesar do grande diferencial do Protocolo no atual Sistema de Cumprimento, os países podem recusar a se submeterem às sanções estabelecidas.

Para Calsing (2005, p.133) o Protocolo de Kyoto é um grande mecanismo no tratamento das questões relacionadas às mudanças climáticas, pois conta com o apoio de diversos países e da comunidade científica que o torna uma inovação no âmbito do Direito dos Tratados Internacionais.

Ao longo de toda a trajetória das negociações ambientais, tendo como ponto de partida principal a Conferência de Estocolmo, podemos observar uma evolução surpreendente do conceito de desenvolvimento sustentável, que atualmente passou a fazer parte não apenas das discussões cientificas, acadêmicas e governamentais, mas tornou-se também acessível ao cotidiano da sociedade.

Atualmente, as mudanças climáticas continuam sendo tema pertinente nas negociações internacionais, segundo o quarto informe do (IPCC), a falta de uma redução efetiva das emissões limita a possibilidade de alcançar níveis de estabilização mais baixos aumento o risco de que se agravem os impactos gerados.

Nesse sentido, alguns esforços foram realizados em prol desta problemática em Copenhague na XV Conferencia das Partes (COP 15) da Convenção Marco das Nações Unidas sobre Mudanças Climáticas, considerada a maior manifestação na história das convenções sobre meio ambiente das Nações Unidas (HOPPSTOCK, 2010).

"Ante un reto de tal magnitud, es fundamental la cooperación multilateral, y la satisfactoria conclusión de las negociaciones mundiales en curso sobre el cambio climático sería el primer paso a fin de lograr un desarrollo sostenible para las generaciones futuras. El cambio climático es un problema que no puede esperar. Es una amenaza para el desarrollo, la paz y la prosperidad futuros a la que toda la comunidad de naciones debe hacer frente con la 
mayor urgencia posible." Pascal Lamy, Director General de la OMC, y Achim Steiner, Director Ejecutivo del PNUMA.

Apesar da expectativa gerada em relação aos possíveis acordos que poderiam ser firmados na tentativa de responder aos desafios das mudanças climáticas os resultados obtidos pela (COP15) foram considerados pouco significativos com apenas o desenvolvimento de um documento intitulado "Copenhagen Accord" considerando incapaz de certa forma de solucionar o impasse existente e bastante questionável no que diz respeito a sua natureza e validez para a negociação (OYUEL, 2010)

Entretanto, é impossível iniciar qualquer analise da referida (COP) sem retomar algumas idéias fundamentais do denominado Plano de Ação de Bal $i$ adotado durante a XIII Conferência das Partes (COP13), em 2007 na Indonésia que determinou pilares para solucionar as questões de mudanças climáticas tais como: a visão compartilhada para ação de cooperação em longo prazo; a mitigación; a adaptação; o desenvolvimento; a transferência de tecnologia e a criação de capacidade e financiamento (HOPPSTOCK, 2010).

O plano buscava estabelecer as bases para a negociação de um instrumento de caráter vinculante para substituir o Protocolo de Kyoto após 2012. Nesse contexto, os países desenvolvidos deveriam assumir compromissos mensuráveis e identificáveis de mitigação, entretanto, os países em desenvolvimento relutavam em adotar as mesmas medidas estipuladas e defendiam a aplicação de formulas especificas a cada economia ((ICTSD), 2008) .

A (COP13) sem duvida contribuiu para que as mudanças climáticas assumissem novamente uma posição relevante no foro das atenções públicas, além disso, determinou dois grupos distintos para a discussão do regime de mudança climática, ou seja, o Grupo de trabalho Ad Hoc sobre compromissos futuros dos países do Anexo I do Protocolo de Kyoto e o Grupo Ad Hoc sobre cooperação em longo prazo no âmbito da Convenção (de acordo com o Plano de Bali 2007).

Segundo Julia Hoppstock (HOPPSTOCK, Cecilia, \& Carlos, 2009), as negociações no âmbito do Grupo sobre os compromissos futuros do Protocolo de Kyoto foram iniciadas em 2005 e o Grupo sobre cooperação refere-se a Convenção Marco das Nações Unidas sobre Mudanças Climáticas Conferencia das Nações Unidas sobre Meio Ambiente e Desenvolvimento em 1992. 
Obviamente, os países poderiam ignorar ou reforçar as ações determinadas em Bali, mas na realidade a previsão era de que seria possível adotar uma decisão com base no mandato do Plano na (COP15), o que infelizmente não aconteceu. A reunião realizada em Copenhague entre o dia 07 e 18 de dezembro de 2009 não abarcou as sugestões dos grupos de negociação no marco da Convenção e do Protocolo de Kyoto mencionados anteriormente.

Quadro 02 - Representa os temas relacionados ao comercio e as mudanças climáticas no Plano de Bali não incorporados ao "Copenhagen Accord".

\begin{tabular}{|c|c|c}
\hline Temas de negociação & $\begin{array}{c}\text { Plano de Ação de } \\
\text { Bali (2007) }\end{array}$ & $\begin{array}{c}\text { Inclusão no "Copenhagen } \\
\text { Accord" }\end{array}$ \\
\hline $\begin{array}{c}\text { Enfoques setoriais } \\
\text { e marítimo internacional }\end{array}$ & Parágrafo 1 (b) (iv) & Não \\
\hline $\begin{array}{c}\text { Ações setoriais na } \\
\text { agricultura }\end{array}$ & Parágrafo 1 (b) (iv) & Não (b) (iv) \\
\hline
\end{tabular}

O "Copenhagen Accord" prorrogou o mandato de ambos os grupos de negociação com a apresentação de seus resultados para (COP16) em Cancúm no México em 2010. Praticamente nas ultimas horas da Conferencia os dirigentes dos Estados Unidos, Brasil, China, Índia e Sul da África apresentaram um posicionamento relevante para o seu entendimento, mas por outro lado Venezuela, Bolívia, Nicarágua e Sudão apresentaram fortes objeções em relação ao seu conteúdo (HOPPSTOCK J. , 2010).

Nesse sentido, o texto do acordo se restringiu em determinar que os países providenciassem informações nacionais sobre as forma de combate do aquecimento global mediante as consultas internacionais, já os países desenvolvidos se comprometeram em reduzir $80 \%$ de suas emissões até 2050 e para 2020 reduzir até $20 \%$ - a redução proposta aquém da sugerida pelo (IPCC) que estabeleceu uma redução entre $25 \%$ e $40 \%$ até 2020 - além de promover de maneira adequada recursos financeiros, tecnológicos e capacitação para implementação da adaptação dos países em desenvolvimento.

Todavia, com respeito às questões de adaptação, o parágrafo 8 do texto do acordo expressa claramente o compromisso por parte dos países desenvolvidos em investirem 100.000 bilhões de dólares anuais em 2020 para atender as necessidades dos países em desenvolvimento, assim, o financiamento 
para adaptação deveria ser distribuído através de ajustes com uma representação igualitária dos países (OYUEL A ESTRADA, 2010).

$\mathrm{O}$ texto reconhece pela primeira vez a necessidade de reduzir em $2^{\circ} \mathrm{C} \mathrm{o}$ aumento da temperatura da terra, porém não conseguiu determinar as diretrizes básicas para atingir tal meta. Segundo Lumumba Di Aping negociador chefe do Grupo de países G77 o "acordo apresentou um nível de ambição menor que o esperado" (ELBERS, 2010). O seu maior enfoque na realidade foi para o tema de mitigação com objetivos para os países desenvolvidos e com compromissos voluntários para os países em desenvolvimento como o Brasil.

O parágrafo 4 do acordo descreve que as partes do Anexo I da Convenção que são os Estados identificados desde 1992 como industrializados e responsáveis pelas iniciativas de ações de mitigação assumiriam o compromisso de em 2020 implementar objetivos quantificados de emissões que se refiram globalmente as suas economias nacionais (OYUEL, 2010).

O parágrafo 5 também foi destinado à mesma temática, ou seja, apesar das dificuldades enquanto a sua leitura e analise determina ações de mitigação dos países em desenvolvimento, mantendo, por outro lado, a diferencia caracterizada pelo Plano de Bali em relação aos compromissos assumidos pelos países desenvolvidos e as exigências de implementação de ações no caso dos desenvolvidos.

Entretanto, não existe duvida que a discussão desta questão parece mesmo interminável, os países em desenvolvimento, por exemplo, sustentam ainda o argumento da aplicação de responsabilidades comuns, mas diferenciadas, o que significa que somente os países desenvolvidos deveriam assumir compromissos vinculantes de redução (HOPPSTOCK, Cecilia, \& Carlos, 2009).

Essa idéia pode remeter ao seguinte questionamento: Quem deveria promover o financiamento para mitigação e adaptação das mudanças climáticas? No contexto atual essa pode ser uma difícil resposta, primeiro pela divergência existente de posicionamento entre os países principalmente em relação à origem dos fundos públicos e privados e em segundo pelos próprios mecanismos de mercado e medidas de comercio.

O texto também apresenta algumas diferencias em relação ao Protocolo de Kyoto, o primeiro indica que os países em desenvolvimento deveriam formular suas promessas de mitigação, no caso do Protocolo as metas foram claramente definidas, outro ponto importante é que o acordo estabelece a meta para 2020 e não no período de anos conforme o fixado no Protocolo que era (2008-2012). 
Porém, não podemos esquecer as dificuldades em firmar um acordo desta magnitude principalmente ao incorporar atores economicamente diferentes e com interesses próprios. A adesão a propósitos compartilhados não representa a solução total da situação, pois variáveis como a capacidade de eleição dos meios e o tempo para alcançar determinadas metas pode interferir de maneira significativa no processo.

O desfecho da (COP15) pode afirmar este panorama, sem conclusões efetivas não conseguiu alcançar o acordo esperado devido a sua precariedade jurídica, política e técnica. Segundo James Hansen líder das mudanças climáticas no mundo o fato não é nenhuma surpresa, pois em sua concepção o fracasso das negociações em Copenhague era certo (ELBERS, 2010).

As falhas identificadas neste processo de negociação são inúmeras as quais estão: a ausência de liderança, falência no processo de elaboração, dificuldades em administrar todas as matérias vinculadas (produção, transporte, consumo de produtos e impactos econômicos) e a falta de vontade política (OYUEL, 2010).

Em termos gerais os principais atores do comercio internacional não aceitam que as limitações de suas emissões sejam mais severas que as aplicadas aos seus competidores, o que dificulta cada vez mais a produção de acordos satisfatórios a todos. Apesar da tentativa do acordo de vincular temas comerciais e mudanças climáticas, não foi possível definir uma solução para o tema (HOPPSTOCK J. , 2010).

O Brasil apresentou um posicionamento firme e relevante no âmbito das negociações da (COP15), em seu discurso na plenária o ex presidente Lula da Silva esclareceu que o mundo não chegaria a um acordo climático com a assinatura de qualquer documento sem um compromisso forte com metas de redução de emissões de $\mathrm{CO}_{2}$ e a garantia do direito das nações mais pobres de se desenvolverem (Brasil, Acordo climático não sairá com meias palavras e barganhas, 2009).

O ex-presidente também destacou a atuação do Brasil com a apresentação de uma proposta de redução de emissões com ações na agricultura e principalmente na redução do desmatamento da Amazônia em 80\% até 2020. Afirmou ainda que o Brasil não iria barganhar suas metas e que os princípios do Protocolo de Kyoto e da Convenção deveriam ser respeitados.

Contudo, pode-se concluir que os desafios enfrentados pela comunidade internacional no tocante a problemática ambiental ainda não foram totalmente vencidos, nesse sentido será necessário ações futuras cada vez efetivas para 
evitar que a falta de um consenso multilateral conduza a proliferação de iniciativas individuais o que prejudicaria ainda mais a situação.

\section{CONSIDERAÇÕES FINAIS}

Diante de um panorama de grande complexidade, destaca que a partir de 1972, o meio ambiente foi discutido de forma ampla e transferido para o âmbito das negociações internacionais, que geraram convenções primordiais na trajetória que se segue em busca de um mundo sustentável.

Nesse contexto, o Brasil se inseriu no novo cenário configurado e alterou seu posicionamento adotado na Conferência de Estocolmo, caracterizado pela resistência em aceitar a Agenda Ambiental estabelecida, assumindo posteriormente em 1992 suas responsabilidades e aderindo o conceito do desenvolvimento sustentável, o que contribuiu de forma enfática para a evolução da atuação brasileira nas negociações ambientais internacionais.

Por tanto, é necessário considerar a importância da atuação do Brasil nas conferências ambientais internacionais, onde desempenhou um papel muitas vezes de mediador, de líder e de inovador ao colaborar em 1992 e 1997, para a consolidação de ações para o estabelecimento concreto do desenvolvimento sustentável.

Porém, apesar da ampliação da conscientização ambiental brasileira e da evolução do pensamento político ambiental relativo ao tema, observase também, que o País necessita ainda de maiores investimentos e fiscalização continua e transparente para desenvolver mecanismos internos capazes de solucionar as dificuldades de degradação ambiental, principalmente no tocante a Amazônia e ao cerrado.

Desta forma, estima-se que os resultados aqui apresentados possam incentivar novos estudos acadêmicos com a profusão de novas pesquisas para destacar a importância do meio ambiente nas relações internacionais e contribuir para a manutenção do desenvolvimento sustentável no Brasil.

\section{REFERÊNCIAS}

(ICTSD), I. C. (fev. de 2008). Conferência de Bali abre caminho para Acordo Climático Global. Acesso em 01 de maio de 2012, disponível em ICTSD: <http://ictsd.org/i/news/10606/> . Acesso em 01 de maio de 2012. 
Brasil. Relatório para Conferência das Nações Unidas sobre Meio ambiente e Desenvolvimento: desafio do desenvolvimento sustentável. Brasília: Clima, 1991.

Brasil. Conferência das Nações Unidas sobre Meio Ambiente e Desenvolvimento: Relatório da Delegação Brasileira. Brasília: Fundação Alexandre Gusmão, 1993.

Brasil. (dezembro de 2009). Acordo climático não sairá com meias palavras e barganhas Disponível em Planalto: $<$ http://blog.planalto.gov.br/ acordo-climatico-nao-saira-com-meias-palavras-e-barganhas/> Acesso em 01 de maio de 2012.

\section{CALSING, R. d. O protocolo de Quioto e o Direito do} desenvolvimento sustentável. Porto Alegre: Sergio Antonio Fabris, 2005.

ELBERS, J.. La cumbre climática de Copenhague versus el cambio climático real. Disponível em Programa de Estudios Socioambientales Flacso Ecuador: <http://www.flacsoandes.org/dspace/bitstream/10469/2184/ 10/05.\%20La\%20Cumbre\%20Clim\%C3\%A1tica\%20de\%20Copenh ague $\%$ E2\%80\%A6\%20J\%C3\%B6rg\%20Elbers.pdf>. Acesso em 01 de maio. 2012.

HOPPSTOCK, J. omercio y cambio climático: perspectivas y posiciones en Copenhague. Revista del CEI : Comercio exterior e Integración, 17, 2010.

HOPPSTOCK, J. P., Cecilia, G., \& Carlos. Comercio y Cambio Climático: el camino hacia Copenhague. Serie de Estudios del CEI, $13,2009$.

MACHADO, J. R., \& RODRIGUES, D.. Meio ambiente, economia, relações internacionais e sustentablidade não equilibrada: novos objetivos no pragmatismo diplomático. In: E. A. SASTRE, Encruzilhada da Universidade Particular: caminhos e possibilidades. Brasília: Universa, 2006. 
MAGNOLI, D. O mundo contemporâneo: relações internacionais, 1995-2000. São Paulo: Moderna, 1996.

Ministério do Meio Ambiente. (s.d.). Agenda 21 Brasileira.Disponível em Minisério do Meio Ambiente: $<$ http://www.mma.gov.br/index.php?ido $=$ conteudo.monta\&idEstrutura $=18 \&$ idConteudo $=908>$. Acesso em 20 de set. 2007

Ministério do Meio Ambiente. (s.d.). DECLARAÇÃO DO RIO SOBRE MEIO AMBIENTE E DESENVOLVIMENTO. Disponível em Ministério do Meio Ambiente: $<$ http://www.mma.gov.br/index.php?ido= conteudo.monta\&idEstrutura $=18 \&$ idConteudo $=576>$ Acesso em 12 de set. 2007.

OYUEL A ESTRADA, R. (2010). Acuerdo de Copenhague: las negociaciones sobre el cambio climático después de la XV Conferencia. Argentina. evista del CEI : Comercio exterior e Integración, 2010.

PNUD. (s.d.). Mecanismo de Desenvolvimento Limpo (MDL). Disponível em Pnud: http://www.pnud.org.br/saneamento/reportagens/ index.php?id01=831\&lay=san, Acesso em 20 de set. 2006.

Sarney, J. Protocolo de Quioto e Legislação Correlata. Brasília: Senado Federal, 2004.

Trigueiro. PROTOCOLO DE KYOTO: O desafio do superaquecimento global. Disponível em Globo: <http:/video.globo.com/Videos/Player/Noticias/ 0,,GIM467992-7823-PROTOCOLO+DE+KYOTO+O+DESAFIO + DO+SUPERAQUECIMENTO+GLOBAL,00.html>. Acesso em 15 de set. 2007.

Vargas, F. G. MEIO AMBIENTE BRASIL: avanços e obstáculos pósRio 92. São Paulo: Estação Liberdade, Instituto Socioambiental, Fundação Getúlio Vargas, 2002. 
Viola, E. VIOLA. Eduardo. A Globalização da Política Ambiental no Brasil, 1990-1998. Disponível em A Globalização da Política Ambiental no Brasil, 1990-1998.: <http://168.96.200.17/ar/libros/lasa98/Viola.pdf>. Acesso em 23 de set.2006.

Artigo recebido em: 10/08/2014 Aprovado para publicação em: 22/08/2014

Como citar: ALMEIDA, Wilson. RODRIGUES, Débora. SANTANA, Hadassah Souza. O posicionamento do Brasil nas negociações internacionais sobre temas de meio ambiente. Revista do Direito Público. Londrina, v.9, n.2, p.183-202, mai./ago. 2014. DOI: 10.5433/1980511X.2014v9n2p183. 